\title{
3. The neurosurgeon as baseball fan and inventor: Walter Dandy and the batter's helmet
}

\author{
Ryan Brewster, BA, Wenya Linda Bi, MD, PhD, Timothy R. Smith, MD, PhD, MPH, \\ William B. Gormley, MD, MPH, lan F. Dunn, MD, and Edward R. Laws Jr., MD \\ Department of Neurosurgery, Brigham and Women's Hospital, Harvard Medical School, Boston, Massachusetts
}

\begin{abstract}
Baseball maintains one of the highest impact injury rates in all athletics. A principal causative factor is the "beanball," referring to a pitch thrown directly at a batter's head. Frequent morbidities elicited demand for the development of protective gear development in the 20th century. In this setting, Dr. Walter Dandy was commissioned to design a "protective cap" in 1941. His invention became widely adopted by professional baseball and inspired subsequent generations of batting helmets. As a baseball aficionado since his youth, Walter Dandy identified a natural partnership between baseball and medical practice for the reduction of beaning-related brain injuries. This history further supports the unique position of neurosurgeons to leverage clinical insights, inform innovation, and expand service to society.
\end{abstract}

http://thejns.org/doi/abs/10.3171/2015.3.FOCUS1552

KEY WORDS Walter Dandy; baseball helmet; head trauma; traumatic brain injury; protective gear; innovation

$\mathrm{O}$ $\mathrm{N}$ June 1, 1940, the division-leading Brooklyn Dodgers took the field against the Chicago Cubs early in their Major League Baseball (MLB) season. ${ }^{26}$ Standing at shortstop for Brooklyn was Pee Wee Reese, a 21-year-old rookie who had proven himself a mainstay on the club's roster. Yet what happened during this particular contest would bring an abrupt halt to the good fortunes of the Dodgers and their young star. An errant fastball by Chicago pitcher Jake Mooty struck Reese on the side of the head, a fraction of a second after being released. Protected only by a canvas fielding cap, Reese absorbed the full impact of the projectile and fell limp to the ground.

Reese was able to return to the game of professional baseball without any significant neurological damage. This incident, however, was one of the many head injuries in the hazardous history of the "beanball"-a euphemism referring to a baseball pitched at a batter's head-throughout the mid-20th century. Between 1888 and 1951, "beaning" was the major cause of fatalities in the sport, claiming the lives of hundreds of amateurs, 9 minor league players, and 1 major leaguer, Cleveland Indians shortstop Ray Chapman in $1920 . .^{12}$ Beyond the cases of reported lethal "beanings," an even greater number of morbid concussions, skull fractures, and other traumatic brain injuries (TBIs) escaped documentation.
Initial efforts to devise protective headgear were modest, despite the obvious hazards posed by the beanball. In 1905, the A.J. Reach Company patented the "Reach Pneumatic Head Protector for Batters," a device best described as an inflatable boxing glove encasing the head (Fig. 1). ${ }^{23}$ Hall-of-Fame catcher Roger Bresnahan debuted this helmet prototype in 1907, but it failed to gain wide adoption..$^{15}$ The following two decades saw further experimental headgear prototypes, from sponge wraps to cork cushioning, with no permanent success..$^{17}$ In 1937, Mickey Cochrane, then player-manager for the Detroit Tigers, renewed public concern regarding the beanball when he sustained a careerending skull fracture. ${ }^{1}$ That same year, the minor league Des Moines Demons tested the use of polo headgear in a game. ${ }^{19}$ These early helmets were cumbersome, heavy, and restrictive, which precluded widespread adoption by the league. By 1939, an aluminum helmet liner had been developed by major league shortstop Skeeter Newsome, which was described by Popular Science magazine as "strong enough to absorb the shock of a thrown or batted ball, but light enough to be worn without discomfort."21

At the beginning of the 1940s, a wave of "beanball wars" emerged, during which pitchers would intentionally throw at batters as retaliation or to intimidate the opposing team. ${ }^{29}$ League officials levied numerous penalties to discourage these attacks, but no rule change could 


\section{Ball Players}

\begin{abstract}
THIS NEW PATENTED
Reach Pneumatic Head Protector For Batters

Was designed by the largest makers of sporting goods, in your interest, and is thoroly practical in all respects.
\end{abstract}

PATENTED JANUARY 24, 1905

\section{Price \$5.00 each}

\section{Every Ball Team Should} Have One.

So many batters have been put out of the game by being struck in out of the game by beins struck in teinand for pitclied bills thit the beinand rusedustidesisnthis Pne matic protector which we know will matic Protector which we knuw
preventinjuries of this nat ure.

It is not only the loss of the player's services that is in. volved, but his usefulness to a team is impairte even after he recovers, as he is timid when approaching the plate, which necessarily effects his batting.

Our Protector will restore the confidence of the player. It protects every part that is liable to injury. With the knowledge that he is thoroughly protected, the player will be as valuable to a team as he vas for merly.

It will also inspire confidence in the timid batter who is afraid to hug the plate which is the secret of all successtul batters.

\section{FOR SALE BY}

\section{A. J. Reach Co., Philadelphí, Pa. and by aLl SPORTING.GOOdS DEALERS}

FIG. 1. Early batting helmet prototype. Advertisement for the A.J. Reach head protector for baseball players.

realistically curtail the more prevalent accidental fastball strike to the head. Seeking other prophylactic strategies, the National League mandated experimentation with helmets in 1941 to minimize "the danger to batters from wild pitches." 9

Beaning batters had become so prevalent that the phrase "Beanball, Inc." became wordplay for "Murder, Inc.," a euphemism used to describe 1930s and 1940s crime syndicates. ${ }^{16}$ Brooklyn Dodgers general manager Larry MacPhail responded swiftly to Beanball Inc. because of the head injuries sustained in 1940 by Reese and his teammate Joe Medwick. These head injuries became a rallying point for McPhail and National League President Ford Frick to galvanize the targeted development of protective headgear. ${ }^{14}$ McPhail partnered with orthopedist Dr. George E. Bennett of the Johns Hopkins School of Medicine. The two men appreciated that a prerequisite to successful helmet design was a thorough understanding of the anatomical features of the skull and brain and the biomechanics associated with TBI. To fill this gap in neuroanatomical knowledge, they approached one of Bennett's colleagues at Johns Hopkins, and one of the world's experts on the brain, famed neurosurgeon Walter Edward Dandy. ${ }^{27}$

\section{Dandy and the Advancement of Batting Helmet Design}

Walter Dandy had harbored a keen interest in baseball ever since his childhood. He was described by one of his roommates as a "hard student, a hard player and a hard sleeper."10 Despite this reputation, he often balanced his studies in secondary school, and later at the University of Missouri, with pick-up baseball games outside his dormitory. Not even his rigorous clinical assistantship under Dr. Harvey Cushing at Johns Hopkins could stop him from playing hardball upwards of "three times a week"; Dandy served as the captain of the Johns Hopkins baseball team.? In fact, Dandy credited baseball for helping to refine his surgical techniques. "Don't you know I have been thinking how valuable it has been to me to have played baseball, and all outdoor exercises and manual work" he wrote in a 1914 letter to his parents, "It has made me quite adept with my hands and I can really operate very skillfully when given a chance." ${ }^{8}$ The sport remained one of his favorite pastimes throughout his later years, which were filled by following the fortunes of the Baltimore Orioles and the Washington Senators, and spoiling his children with athletic gear. He would often ride on the train to New York to watch baseball games, and write papers on the desk in his roomette traveling to and forth.

On rare days when he had no operative cases, Dr. Dandy would occasionally invite his "Brain Team" to Oriole Park in Baltimore. There he observed the hierarchy that existed in the Hopkins surgical residency. The Chief Resident sat next to Dandy, followed in order by the Assistant Resident, and the two interns. When Dandy realized that they had not had lunch, he ordered a beer and two hamburgers each for the residents, and a Coke and one hot dog each for the interns. ${ }^{10}$

Dandy was exposed early in his medical career to the perils of the beanball. One of his first significant surgical cases of 1912 involved a patient with a "big (cranial) cyst or sack of water which was the result of being struck by a baseball."7 So when Bennett and MacPhail commissioned Dandy nearly three decades later to work on a protective head covering, he eagerly agreed, moved by both personal and professional motives.

Dandy derived inspiration from the contemporary jockey's helmet to create an "armored cap," consisting of two featherweight plastic plates that were inserted into either side of a player's fabric hat (Fig. 2). ${ }^{24}$ To construct the prototype, the plastic was cut and sewn into the cap by Mrs. Walter Dandy and two of their daughters, Mary Ellen and Kitty (personal communication from Ms. Mary Ellen Dandy Marmaduke). A later version of the cap resides in the Baseball Hall of Fame in Cooperstown, New York. The Chicago Tribune profiled the helmets shortly after their introduction in March 1941:5

Zippered pockets are cut in each side of a regulation baseball cap. Into one of these pockets, on the side that faces the pitch- 


\section{UNITED STATES PATENT OFFICE}

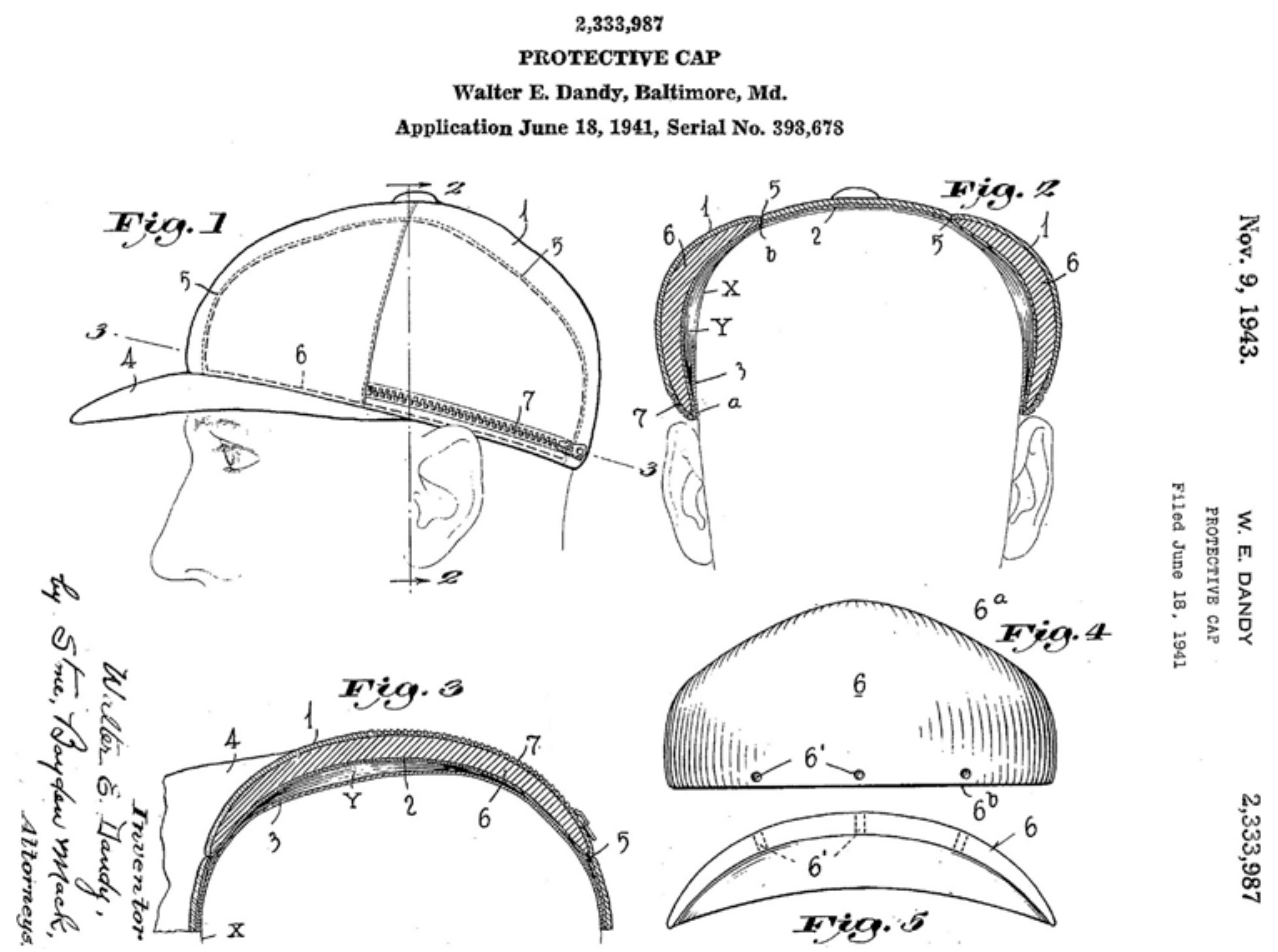

FIG. 2. U.S. Patent No. 2,333,987: Walter Dandy's protective cap. Dr. Walter Dandy designed two curved, plastic guards that were inserted on either side of a batter's canvas fielding hat. The helmet was introduced to the MLB in 1941 and was widely adopted for the decade thereafter. Today, one of Dandy's caps can be found on display in the National Baseball Hall of Fame in Cooperstown, New York. From the patent document:

Referring to the drawing in detail, the cap, which may be of the usual construction, comprises an outer fabric body (1) and a lining (2). Inside the lining, and extending around the lower edge of the cap, is the usual sweat band (3), and the cap may be provided with the customary visor (4). A pocket is formed at each side of the cap between the fabric body and lining, as by means of a seam or row of stitching (5). In this pocket is enclosed my improved shield or guard member, designated in its entirety by the reference numeral 6 . This shield or guard member is relatively rigid and may be molded from wood pulp, indurated fiber, or plastic material such as some of the synthetic resins, either with or without reinforcing threads or fabric. As shown, it is preferably thicker in its middle portions, tapering to relatively thin edges. The shield or guard member is of double curvature, that is to say, it is curved both horizontally and vertically, as viewed in Fig. 4, and the degree of curvature is preferably such that the shield bears against the head $(X)$ of the wearer only at its margins or edges, as indicated at $a$ and $b$ in Fig. 2, so that a space or cavity $(Y)$ is formed between the body of the shield and the head of the wearer. The upper edge (6a) of the shield is preferably curved or arcuate, as shown in Figs. 1 and 4, while the lower edge (6b) is substantially straight. In the form of the invention shown in Figs. 1,2 and 3 , the shield receiving pocket is provided with an opening in the fabric body of the cap, preferably near the lower edge, which opening is closed by means of a suitable slide fastener (7).

er, the batter will slip a plastic plate which is about a quarter of an inch thick and little more than an ounce in weight. The plate, about the width and length of a man's head, covers the vulnerable area from the temple to about an inch behind the ear.

Functionally, the lightweight protective guards were engineered to disperse the mechanical energy from the blow throughout the entire head instead of being absorbed in a localized area. One major barrier to widespread adoption of protective headgear had been the perception by players that wearing a safety device signaled both weakness and cowardice. Others complained that previous iterations of the protective helmet had an awkward shape that interfered with lines of sight. Dandy circumvented these concerns by positioning the plate within the inner liner of the baseball cap, where it wasn't "cumbersome and so conspicuous that everybody could see it." Having answered to the dual imperatives of safety and appearance, the helmet earned the praise of MacPhail in 1941 as "the biggest thing that has happened to the game since night baseball." 5 The Brooklyn general manager promptly mandated that all members under the Dodgers franchise wear the invention and wrote in a letter to Dandy (February 7 , 1941; archived in the Giamatti Research Center of the National Baseball Hall of Fame):

If there is any possibility of having Dupont get out a few samples so that these caps could be fitted and used in our training camp, I would very much like to have it done regardless of the expense involved in getting out the samples. After using the device in training camp, caps and molds could be altered or constructed so that the device is . . . available for the opening of the season.

Dandy's "protector for batsmen" marked an important milestone in the advancement of baseball headgear. Its potential was realized almost immediately when Dodgers rookie Pete Reiser was struck in the head by a ball in 
late April 1941. ${ }^{13}$ Even though the ball struck Reiser too low on the temple for maximal protection, the mild concussion and localized blood clot he suffered were likely minor compared with the injuries he might have suffered without the protective cap. His treating physician at Caledonia Hospital in Brooklyn noted, "He's a very lucky man because he certainly would have had a fractured skull if it weren't for the helmet which absorbed part of the shock."13 Soon thereafter other MLB teams, including the Washington Senators, the Chicago Cubs, and the New York Giants, followed suit in donning armored caps. At the end of the season, the St. Petersburg Times headlined: " 41 baseball season marked by war, introduction of the helmet." 6

Unfortunately, early implementation of the protective cap was marred by a lengthy patent dispute between Dandy and MacPhail. Dandy maintained an altruistic stance, wishing to license the invention in his name with no financial strings attached: "All I want is credit for helping baseball," he affirmed, "and I surely expected this degree of gratitude in return for my efforts." 10 Two years would pass before a Board of Examiners would entitle Dandy to the patent, which was eventually issued and then donated to baseball in November $1943 . .^{10}$

\section{Continued Evolution in Helmet Design}

Ultimately, Dandy and his protective cap overcame the social barriers to batter headgear. It was considered the standard for baseball at all levels until the immediate precursor to the modern helmet was unveiled by Pittsburg Pirates general manager and American Cap, Inc., founder Branch Rickey in 1952 (Fig. 3). ${ }^{20}$ Unlike the plastic inserts protecting only the side of the head, the new fiberglass and polyester resin helmet designed by Pirates executive Charlie Muse provided full cranial coverage. Additionally, a leather-padded interior lined the hard shell to ensure an individualized, secure fit. The technology was rapidly adopted, and what were previously belittled as "bowlers" and "miner's helmets" suddenly became assets to player safety. ${ }^{2}$ This change in attitude was cemented by reforms in 1956 and 1958 that made head protection mandatory for batters in the National and American Leagues, respectively.

During the latter half of the 20th century, innovation in helmet design stemmed principally from youth Little League ball. Dr. Creighton Hale, an exercise physiologist turned Little League president, infused scientific methodology to the optimization of safety equipment. He devised a pneumatic air cannon that could "fire baseballs at controlled speeds and simulate exact conditions under which helmets [were] going to be impacted." ${ }^{28}$ Data could then be extrapolated to batters in live play. This research led to the development of lightweight polycarbonate, double ear-flapped helmets rated to withstand velocities commensurate with professional pitching. The global coverage protected the occiput and the temples better than previous models. Little League Baseball required all teams to wear the new headgear beginning in the late 1950s. The outcome was resoundingly positive; the incidence of TBI among youth teams declined almost instantly and precipitously. ${ }^{4}$ Having clearly demonstrated its efficacy, the
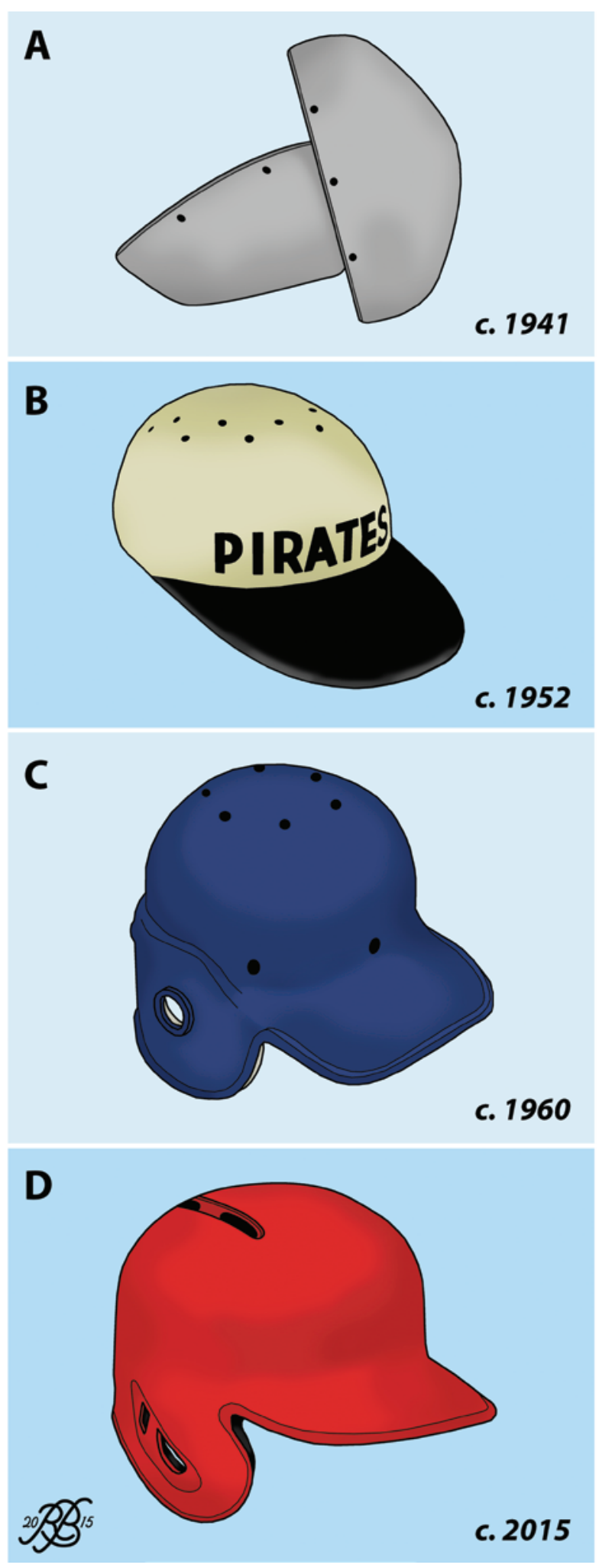

FIG. 3. Milestones in batting helmet development. Schematics of protective shields developed by Dr. Walter Dandy (A); the immediate forerunner to the modern helmet, designed by Branch Rickey and the American Baseball Cap Company (B); a more resilient device following rigorous performance testing led by Dr. Creighton Hale (C); and the modern Rawlings S100 Pro Comp (D). Copyright Ryan Brewster. Published with permission. 
device became adopted by professional baseball. In 1971, the use of helmets-not just inserts or liners-became compulsory for all minor and major league athletes. An addendum was later made in 1983, when helmets with at least one earflap had to be worn at the plate.

\section{Contemporary Challenges and Breakthroughs}

Although the use of batting helmets has reduced some risks associated with baseball, head trauma continues to be a major safety concern. The American Association of Neurological Surgeons (AANS), citing data from the Consumer Product Safety Commission's National Electronic Injury Surveillance System (NEISS), reported an increase in the number of baseball-specific head injuries between 2008 and 2009, from 26,964 to 38,394 (http://www. cpsc.gov/en/Research--Statistics/NEISS-Injury-Data/). Furthermore, nearly a quarter of all concussions sustained in MLB are because of beaning, making it one of the leading mechanisms of injury in the league. ${ }^{25}$ The figure rises to $51 \%$ at the high school and college level. ${ }^{11}$ The persistence of head trauma injuries is resistant to regulatory action. For example, despite large fines and austere penalties levied against offenders, one batter was struck by a pitch in every third game in the National League during 2009, a nearly 50\% increase in incidence compared with 1967 (see MLB Batting Encyclopedia at http://www.baseballreference.com/leagues/MLB/bat.shtml). As rule changes proved inadequate to stem the growing rate of head injury, authorities focused major initiatives on protective gear.

Rawlings Corporation, the official MLB helmet supplier, has spearheaded the most recent phase in headgear evolution. Several iterations in design over the past decade have led to the current baseball standard, the S100 Pro Comp. ${ }^{3}$ The helmet has the same basic dimensions as its mid-20th century predecessors; however, fabricating the shell with aerospace-grade carbon fiber/epoxy resin composite affords a compact package that is $300 \%$ stiffer and 130 times stronger than previously used materials. ${ }^{22}$ This advancement in protective wear has been possible only through cooperation among material scientists, biomechanical engineers, and physicians, among many others. The neurosurgeon, in particular, is an important bridge between medicine and commercial innovation.

\section{Conclusions: Neurosurgeon as Physician and Innovator}

As exemplified by Walter Dandy's role in the design of the baseball helmet, neurosurgeons are uniquely positioned to leverage their clinical insights beyond the realm of individualized patient care to impact broader policy changes through innovation and entrepreneurship. A natural partnership between neurosurgery and athletics has led the movement to understand, circumvent, and treat sportsrelated head injuries. The history of the batting helmet underscores this relationship. As previously discussed, most prototypes before the 1940s resulted from user-centered innovation. Players, coaches, and other direct beneficiaries were self-directed to address their protective needs. Dandy led pioneering neurosurgeons to become accountable for preventative strategies to reduce head injury. Although his protective cap represented just one stage in the evolution toward the modern baseball helmet, he played a pivotal role in bridging the medical community with the athletic enterprise. This liaison expands the perception and influence of neurosurgery as a small subspecialty field into a greater critical service for society. The New York Times aptly summarized Dandy's legacy in his obituary in 1946: "He devised many methods of operating"; the subheading reads, "Co-designer of baseball helmet."18

\section{Acknowledgments}

We are grateful to Ms. Mary Ellen Dandy Marmaduke for critical review and input on this paper.

\section{References}

1. Associated Press: Mickey Cochrane "through" as player, he tells Williams. Palm Beach Post. June 27, 1937; 15

2. Associated Press: Obituary: Charlie Muse; created baseball batting helmet. Washington Post. May 17, 2005. (http://www.washingtonpost.com/wp-dyn/content/article/2005/05/16/AR2005051601343.html)[Accessed May 11, 2015]

3. Belson K: Now batting: a stronger, mandatory helmet. New York Times. February 20, 2013. (http://www.nytimes. com/2013/02/20/sports/baseball/now-batting-a-strongermandatory-baseball-helmet.html) [Accessed April 30, 2015]

4. Caine DJ, Maffulli N (eds): Epidemiology of Pediatric Sports Injuries: Team Sports. Basel, Switzerland: Karger, 2005, pp 9-30

5. Chicago Daily Tribune: McPhail orders use of helmets in Dodger's chain. March 9, 1941; E1

6. Considine B: '41 baseball season marked by war, introduction of helmet. St. Petersburg Times. May 20, 1941; 11

7. Dandy W: Letter 04/06/12. Congress of Neurological Surgeons: Walter E. Dandy Letters. (https://www.cns.org/ about-us/history/walter-e-dandy/letter/3396) [Accessed April 30, 2015]

8. Dandy W: Letter 03/01/14. Congress of Neurological Surgeons: Walter E. Dandy Letters. (https://www.cns.org/ about-us/history/walter-e-dandy/letter/3545) [Accessed April 30, 2015]

9. Dawson J: National League annual meeting; schedule approved. New York Times. February 5, 1941

10. Fox WL: Dandy of Johns Hopkins. Baltimore: Williams \& Wilkins, 1984

11. Gessel LM, Fields SK, Collins CL, Dick RW, Comstock RD: Concussions among United States high school and collegiate athletes. J Athl Train 42:495-503, 2007

12. Gorman RM, Weeks D: Death at the Ballpark: A Comprehensive Study of Game-related Fatalities of Players, Other Personnel and Spectators in Amateur and Professional Baseball, 1862-2007. Jefferson, NC: MacFarland, 2009, pp 9-28

13. Jacobson S: Pete Reiser: The Rough-and-Tumble Career of the Perfect Ballplayer. Jefferson, NC: McFarland, 2004, pp 70-71

14. Kirksey G: National League heads to discuss batters' helmets. Pittsburgh Press. June 30, 1940; 11

15. Ledger K: Safety did not come first. Sports Illustrated 87:9, 1997

16. McKelvey GR: The MacPhails: Baseball's First Family of the Front Office. Jefferson, NC: McFarland, 2000, p 47

17. Morris P: A Game of Inches: The Stories Behind the Innovations That Shaped Baseball: The Game on the Field. Lanham, MD: Ivan R. Dee, 2006, p 443 
18. New York Times: Dr. W.E. Dandy Dies, April 20, 1946; 13

19. New York Times: To try baseball helmet: protection against 'beanball' to be tested in Iowa today. May 30, 1937; 47

20. O'Toole A: Branch Rickey in Pittsburgh: Baseball's Trailblazing General Manager for the Pirates, 1950-1955. Jefferson, NC: McFarland, 2000, p 78

21. Popular Science: Baseball player wears protective helmet. Popular Science 35:80, 1939

22. Rawlings Sporting Goods Company: MLB Players to Debut Rawlings S100 Pro Comp Batting Helmet. (http:// www.prnewswire.com/news-releases/mlb-players-to-debutnew-rawlings-s100-pro-comp-batting-helmet-this-season-146991495.html) [Accessed April 30, 2015]

23. Richter FC (ed): Reach's Official American League Baseball Guide, 1905. Philadelphia: A.J. Reach Company, 1905

24. Rushin S: The 34-Ton Bat: The Story of Baseball as Told Through Bobbleheads, Cracker Jacks, Jockstraps, Eye Black, and 375 Other Strange and Unforgettable Objects. New York: Little, Brown, 2013

25. Schwindel LE, Moretti VM, Watson JN, Hutchinson MR: Epidemiology and outcomes of concussions in Major League Baseball. Ann Orthop Rheumatol 2:1022, 2014

26. Spatz L (ed): The Team that Forever Changed Baseball and America: The 1947 Brooklyn Dodgers. Phoenix: Society for American Baseball Research, 2012, p 39
27. Sutter LM: Ball, Bat and Bitumen: A History of Coalfield Baseball in the Appalachian South. Jefferson, NC: McFarland, 2008, p 87

28. Van Auken L: Play Ball! The Story of Little League Baseball. University Park, PA: Penn State Press, 2001, pp 110-111

29. Weeks J: Mudville Madness: Fabulous Feats, Belligerent Behavior, and Erratic Episodes on the Diamond. Lanham, MD: Taylor Trade Publishing, 2014, p 102

\section{Author Contributions}

Conception and design: Laws, Bi. Acquisition of data: Brewster, Bi. Analysis and interpretation of data: Laws, Brewster, Bi. Drafting the article: Brewster, Bi. Critically revising the article: all authors. Reviewed submitted version of manuscript: all authors. Approved the final version of the manuscript on behalf of all authors: Laws. Study supervision: Laws, Bi.

\section{Correspondence}

Edward R. Laws Jr., Department of Neurosurgery, Brigham and Women's Hospital, 15 Francis St., PBB-3 Boston, MA 02115. email: elaws@partners.org. 